\title{
Spatial geochemical distribution and sources of heavy metals in the sediment of Langat River, western peninsular Malaysia.
}

\begin{abstract}
The present study employed geochemical and multivariate analyses to assess the level of heavy metals ( $\mathrm{As}, \mathrm{Cu}, \mathrm{Cr}, \mathrm{Ni}, \mathrm{Pb}$, and $\mathrm{Zn}$ ) in sediment along the lower reaches of the Langat River. The sediment samples were digested and analyzed for total metals by an inductively coupled plasma-mass spectrometry (ICP-MS). Selected physicochemical parameters such as $\mathrm{pH}$, redox potential (Eh), electrical conductivity (EC), salinity, organic matter and cation exchange capacity (CEC) were also determined. The metal concentration from this study area was compared with interim sediment quality guidelines (ISQG). Most sediment samples did not exceed the ISQG. Geo-accumulation index (Igeo) revealed that certain sampling stations were classified as strongly polluted with respect to As and classified as moderately polluted for $\mathrm{Pb}$. Based on the enrichment factor $(\mathrm{EF})$ values, most sampling stations were categorized as 'very severely enriched to extremely severely enriched for As and only 3\% were moderately enriched. For $\mathrm{Pb}, \mathrm{pH}$, Eh, and $\mathrm{CEC}$ pose considerable influence on the composition of heavy metal in the sediment as confirmed by Pearson correlation. The hierarchical cluster analysis (HCA) revealed that sediment in the study area could be divided into two major clusters. Cluster 1 was mainly affected by the agricultural and industrial activities while Cluster 2 was heavily affected by seawater. The forensic investigation via the use of geostatistical and geochemical approaches revealed two pollution sources: (i) manmade (agricultural and industrial activities), and (ii) natural processes (seawater intrusion and geological weathering). The quantification of heavy metal concentrations thus provides a better understanding of the potential ecological risks and contamination status of the sediment. The vulnerable areas identified in this study should be given the highest priority for mitigation measures in order to alleviate pollution from industries and agriculture areas. The incorporation of source apportionment method to further understand the dynamics of environmental processes is recommended for future studies to assist in identifying possible high pollution-risk areas.
\end{abstract}

Keyword: River sediment; Enrichment factor; Geol-accumulation index; Correlation analysis; Hierarchical cluster analysis. 